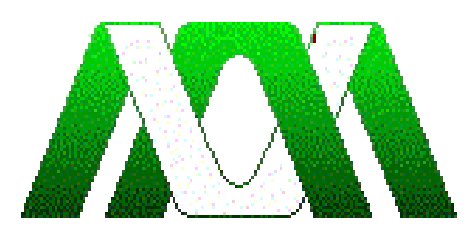

Casa abierta al tiempo

UNIVERSIDAD AUTÓNOMA METROPOLITANA

UNIDAD IZTAPALAPA

DIVISIÓN DE CIENCIAS SOCIALES Y HUMANIDADES

POSGRADO EN CIENCIAS ANTROPOLÓGICAS

El estado y sus reformas estructurales en materia energética:

megaproyectos, territorio y movimientos de resistencia en zonas rurales de México

Gisela Elizabeth Tucuch Santos

\author{
ENSAYO \\ Para obtener el Diploma de Especialización \\ en Antropología Política \\ Director: Dr. Héctor Tejera Gaona
}




\section{El estado y sus reformas estructurales en materia energética: megaproyectos, territorio y movimientos de resistencia en zonas rurales de México}

Introducción

Las políticas y los proyectos destinados a hacer frente al cambio climático a nivel mundial, específicamente aquellos enfocados en lograr la transición energética, responden a la actual economía global en la que predomina el capital agroalimentario y agroenergético basado en la extracción y explotación de recursos naturales (Martínez Reséndiz, 2013:368). En América Latina cada vez es más notable que los gobiernos están abriendo el mercado a los capitales de empresas trasnacionales justificando la necesidad de reducir la emisión de carbono a través del uso de energías renovables y sustentables.

Como bien afirma Cyme Howe (2015a), gran parte de los países latinoamericanos cuentan con un gran potencial para la generación de energía limpia, por lo que son considerados potenciales productores a gran escala de energía geotérmica, biomasa, eólica y solar. Este potencial reconocido mundialmente ha llevado, históricamente, a procesos de extracción de recursos bajo el supuesto de contribuir a la mitigación del cambio climático global. Así, a pesar de que a diferencia de otros países "desarrollados", los países latinoamericanos no han contribuido con grandes cantidades contaminantes la atmosfera colectiva, sí han experimentado la presencia de proyectos de desarrollo internacionales que persiguen sus propias agendas y han sido testigos de cómo los gobiernos nacionales están reestructurando políticas y con ello invirtiendo financieramente en megaproyectos energéticos.

Es así como la acelerada apertura de mercados y participación de Latinoamérica en la generación de energía alternativa permite cuestionar si es su deber o más aún si "es responsabilidad de los estados nacionales latinoamericanos invertir los recursos políticos y económicos para remediar la contaminación del medio ambiente mundial" (Howe, 2015a:232); o si nos encontramos ante nuevas formas contemporáneas de gobierno y poder (Mitchell, 2001), donde el estado, organismos internacionales y empresas transnacionales trabajan en conjunto para cumplir con lo necesario y lograr un "neoliberalismo verde".

En el caso de México, de acuerdo con la Comisión Reguladora de Energía, la Reforma energética, como reforma estructural aprobada en el año 2013 junto con sus leyes secundarias aprobadas en el año 2014, abrió todos los segmentos del sector energético a la participación privada y modificó la estructura del mercado eléctrico al facilitar que tanto empresas nacionales como internacionales se involucren desde la generación y comercialización hasta al suministro de electricidad a lo largo de todo el territorio mexicano (CRE, 2017). De esta manera, los megaproyectos de generación de energía renovable comenzaron a ganar presencia en el $90 \%$ de las entidades federativas del país; siendo Oaxaca y 
Veracruz los estados con mayor número de proyectos, eólicos y de bioenergía respectivamente (SE, 2013).

Bajo este contexto, el presente ensayo buscar discutir cómo se configuró el papel del estado ${ }^{1}$ mexicano después de que se decretó la reforma energética y sus leyes secundarias (2013-2014); pero también cuál ha sido la participación de empresas transnacionales en la explotación de recursos naturales; y cómo se han manifestado las respuestas de las comunidades rurales. Así, en la primera parte se presenta dicha reforma y sus impactos en la apertura del mercado energético. En la segunda, entendiendo los megaproyectos como modelos de despojo se presentan éstos desde la noción de análisis de despojo para la acumulación propuesta por Rodríguez Wallenius (2017); seguido de los movimientos y acciones colectivas de resistencia protagonizados por poblaciones rurales. Para finalizar se reflexiona cómo abordar desde la antropología política las múltiples e interconectadas relaciones sociales, prácticas e ideas de los actores involucrados en la transición energética, evitando así caer en totalidades o esencialismos.

\section{Reforma energética: la apertura total del mercado}

De acuerdo con Romo Rico e Ibarra Puig, a partir de los noventa varios países latinoamericanos abrieron las puertas del sector energético a la inversión extrajera. Como parte del proceso de mundialización, con esta apertura se buscaba elevar la competitividad comercial y las ganancias de divisas a través de exportaciones. En México, por ejemplo, la Inversión Extranjera Directa es vista como una de las fuentes más importantes de captación de moneda extranjera, esto sólo detrás del petróleo y las remesas de los connacionales en el exterior (2009:994).

Precisamente en 1992, con las modificaciones a la Ley del Servicio Público de Energía, en México se hizo efectiva la participación privada en el ramo eléctrico; promoviendo así la participación, operación y posesión de plantas de generación de Productores Independientes de Energía (PIE), mismos que podían autoabastecerse energéticamente, producir a pequeña escala, vender a la Comisión Federal de Electricidad y exportar a través de la cogeneración (Huerta Moreno, 2015:36).

En los años siguientes las privatizaciones del sector energético continuaron dándose a través de reformas legales y marcos regulatorios como el Reglamento de la Ley del Servicio Público de Energía Eléctrica (RLSPEE) en 1993 y 1997; así como la creación de la Comisión Reguladora de Energía (CRE) en 1995 con el fin de servir a intereses de empresarios privados y estipular su participación no solo en la generación autoabastecimiento, cogeneración o pequeña producción, sino también en su uso en emergencias derivadas de interrupciones en el servicio

\footnotetext{
${ }^{1}$ A lo largo del texto se utilizará la palabra "estado" en minúscula con la finalidad de romper con la noción del "Estado" como algo unificado y con autonomía absoluta.
} 
público de energía eléctrica, al igual que su exportación e importación para uso exclusivo de los importadores de la misma (Romo Rico e lbarra Puig, 2009:14)

Como se muestra, todas estas reformas se dieron buscando la apertura del mercado eléctrico y la participación de la inversión privada. Dichas legislaciones secundarias son vistas por Vargas Suárez (2010) como estrategias para "darle la vuelta a la constitución", refiriéndose a lo decretado en el Artículo 27 sobre la responsabilidad directa del estado con la energía como bien público. Si bien se continuaron dando la consolidación de políticas bajo un contexto neoliberal, así como una mayor presión de inversionistas externos, éstas no obtuvieron respuestas o dirección hacia cualquier decreto de apertura privatizadora total ${ }^{2}$.

Esto fue así hasta el año 2013, donde el estado gobernado por Enrique Peña Nieto facilitó la reforma constitucional de los artículos 25, 27 y 28; y con ello la formulación de 9 leyes ${ }^{3}$ y modificación de 12 más, para lograr una reforma integral del sector energético; es decir, una privatización completa. Para entender la Reforma es necesario referir la estructura estatal que facilitó tales cambios, por lo que se reconoce aquí la importancia que tuvo del pacto previamente realizado por el Partido Acción Nacional (PAN), Partido Revolucionario Institucional (PRI) y Partido de la Revolución Democrática (PRD), el llamado Pacto por México, para la aprobación en la cámara de diputados de dicha reforma, así como de sus leyes secundarias. De igual manera los programas oficiales presentados en dicha administración que contenían objetivos, estrategias y líneas de acción dirigidas al sector energético como el Plan Nacional de Desarrollo (PND) 2013-2018; el Programa Sectorial de Energía (PSE) 2013-2018; y el Programa Sectorial de Medio Ambiente y Recursos Naturales (PROMARNAT) 2013-2018.

De esta manera, el principal cambio de estos artículos (especialmente el Art.27) reside en que se establece que, si bien la propiedad de los recursos energéticos del subsuelo son propiedad de la Nación, ésta podrá darlos a particulares mediante asignaciones o contratos. Manteniendo el control del sistema eléctrico nacional y del servicio público de transmisión y distribución de energía eléctrica, así como de la exploración y extracción de petróleo y demás hidrocarburos.

\footnotetext{
${ }^{2}$ Por ejemplo, durante el mandato de Vicente Fox la Suprema Corte de Justicia de la Nación, rechazó las propuestas de modificar la Ley del Servicio Público de Energía Eléctrica al considerarlas anticonstitucionales. Deteniendo así una mayor libertad de participación de la Inversión privada.

${ }^{3}$ Ley de Hidrocarburos; Ley de la Industria Eléctrica; Ley de los Órganos Reguladores Coordinados en Materia Energética; Ley de Petróleos Mexicanos; Ley de la Comisión Federal de Electricidad; Ley de la Agencia Nacional de Seguridad Industrial y de Protección al Medio Ambiente del Sector Hidrocarburos; Ley de Energía Geotérmica; Ley de Ingresos sobre Hidrocarburos; y Ley del Fondo Mexicano del Petróleo para la Estabilización y el Desarrollo.
} 
Por su parte, los cambios al artículo 28 en materia energética se centraron, entre otras cosas, a permitir el establecimiento y fortalecimiento de órganos reguladores como la Comisión Nacional de Hidrocarburos y la Comisión Reguladora de Energía. Con relación a la modificación del artículo 25, se observa el desmantelamiento de las empresas públicas de Petróleos Mexicanos (PEMEX) y Comisión Federal de Electricidad (CFE) al nombrarlas Empresas Productivas del estado. Mismas que quedaran bajo la regulación de leyes estatales que determinen sus normas de organización, funcionamiento y procedimientos de contratación que éstas celebren.

Antes de la reforma, la CFE era vista como un monopolio público encargado del suministro eléctrico en todo el territorio nacional, con capacidad jurídica para establecer contratos con empresas independientes a través de la compra de excedentes de electricidad sin perder su posicionamiento en el mercado. Sin embargo, estos cambios constitucionales implicaron una notable fragmentación de su estructura y poder al transferir la responsabilidad de impulsar y desarrollar la industria eléctrica del país a empresas privadas. De esta manera, a pesar de que se reconocía el progreso continuo de esta empresa pública, el gobierno "desechó la idea de introducir mejoras funcionales para mejorar el modelo híbrido de comparador único. Prefirió pues adoptar un modelo basado en la competencia" (Rodríguez Padilla, 2016:42).

Es así como entre los objetivos de la reforma propuesta por el Ejecutivo Federal, específicamente en el caso del sector eléctrico, reside el permitir a través de vínculos contractuales la participación de inversión privada para modernizar y fortalecer la CFE, abaratar costos de producción, así como la creación de un mercado competitivo que fomente una generación más eficiente, económica y limpia. Para esto último, la Ley de Transición Energética tendrá por objeto regular el aprovechamiento sustentable de la energía; para así cumplir las metas establecidas en materia de generación de energías limpias y de reducción de emisiones, todo esto de una manera económicamente viable y con una notable participación de empresas privadas (Senado de la República, 2015).

Al respecto del fortalecimiento de la CFE, Rodríguez Padilla (2016) señala que dentro de esta empresa no faltaban recursos naturales, capital, tecnología o conocimientos como lo señalaron las autoridades que impulsaban la reforma. Por lo que no se necesitaba eliminar la exclusividad del estado ni la integralidad del servicio público. Por su parte, Clavellina Miller (2014) vaticina que durante los próximos años, más que cumplir con los objetivos planeados, esta reforma logrará el desmantelamiento total tanto de PEMEX como de la CFE, si no se tienden cadenas productivas y de abastecimiento que permitan a las pequeñas y medianas empresas mexicanas articularse con los nuevos entes reguladores del mercado.

Sobra decir que el fomento de una nueva modalidad de participación dentro del mercado energético mexicano no sólo ha sido protagonizado por el estado; ya 
que, al ser un sector con alta rentabilidad, es posible encontrar huella no sólo de fuerzas políticas internas sino también de recursos de organismos financieros internacionales y capital privado nacional y extranjero interesados en la privatización lograda por la Reforma y sus Leyes Secundarias (Huerta Moreno, 2015).

Por lo que estos cambios constitucionales realizados pueden ser vistos como formas de dominación política; en donde el estado "favorece el despliegue de la acumulación del capital a favor de la lógica de la cadena de valor global en las actividades más diversas" entre ellas la energética (Merchand, 2015:117). En el siguiente apartado se abrirá una pequeña discusión sobre el papel que ha tenido el Estado dentro de este sector.

\subsection{El estado y la transición energética en México}

En su prefacio a la obra African Political Systems, A. R. Radcliffe-Brown sostiene que el estado no existe en el mundo fenomenal al ser éste una mera ilusión de los filósofos y por lo tanto puede eliminarse del análisis social. En este orden de ideas rechaza la noción de estado, con frecuencia representado como una entidad superior a los individuos que conforman una sociedad y que se caracteriza por tener entre sus atributos "algo llamado soberanía", voluntad o ser emisor de órdenes. Afirmando así que lo sí existe es una organización; "es decir, un grupo de seres humanos individuales vinculados por un sistema complejo de relaciones" (2010:59).

Por su parte, Philip Abrams califica como radical la afirmación de A. R. Radcliffe- Brown y propone que únicamente se debería abandonar al estado como objeto material de estudio, sea concreto o abstracto, sin renunciar a la idea del estado. Esto no implica dejar a un lado el estudio de las relaciones internas y externas de las instituciones políticas y gubernamentales, ni sus implicaciones con intereses económicos en un complejo general de dominación y sometimiento; más bien asegura que sin postular la realidad de estado "la idea del estado llega a ser un objeto fundamental de estudio, [...] podríamos decir que el estado es la falsa representación colectiva característica de las sociedades capitalistas" (2015:52).

Pierre Bourdieu, asegura que proponerse pensar el estado conduce a retomar por cuenta propia un pensamiento de estado, a aplicar al estado unas categorías de pensamiento producidas y avaladas por el estado y por lo tanto a no reconocer la verdad más fundamental de éste. De esta manera dicho autor considera al estado como $\mathrm{X}$ (por determinar) que reivindica con éxito el monopolio del empleo legítimo de la violencia física y simbólica en un territorio determinado y sobre el conjunto de la población correspondiente. El ejercicio de este tipo de violencia por parte del estado es posible ya que se encarna en la objetividad bajo forma de estructura y de mecanismos específicos y en la "subjetividad" bajo forma de estructuras mentales, de percepción y de pensamiento (1997:98).

Concebir esta idea de estado, que se encuentra presente hasta en lo más íntimo de nuestro pensamiento, permite el análisis de cómo el dominio del Estado 
radica especialmente en el ámbito de lo simbólico (Bourdieu, 1997: 95). Entendiendo, desde una perspectiva bourdiana, el estado como resultado de un proceso de concentración de los diferentes tipos de capital (de fuerza física, económico, cultural y simbólico) que lo convierte en poseedor de una especie de metacapital, otorgando poder sobre las demás clases de capital y sobre sus poseedores.

Bourdieu afirma que esta concentración facilita la emergencia de un capital específico, propiamente estatal, que permite al estado ejercer un poder sobre los diferentes campos y sobre los diferentes tipos particulares de capital. De esto resulta que la elaboración del estado se vincule con la elaboración del campo de poder, siendo éste el espacio de juego dentro del cual los poseedores de capital luchan particularmente por el poder sobre el estado (1997:100).

Es así que con este autor volvemos a la discusión del estado como un proyecto ideológico; esto al señalar que el estado "instaura e inculca unas formas y unas categorías de percepción y de pensamiento comunes, unos marcos sociales de la percepción, del entendimiento o de la memoria, unas estructuras mentales, unas formas estatales de clasificación" (Bourdieu, 1997:117). Y para entender cómo se manifiesta la sumisión inmediata que dicta el orden estatal hay que ver a estas estructuras cognitivas como disposiciones del cuerpo; ya que estas llamadas al orden no son cumplidas de forma automática, sino que se debe estar dispuesto a percibirlas y ejecutarlas.

Ahora bien, lo presentando anteriormente muestra sólo una parte de cómo las aportaciones teóricas desde distintas disciplinas han ido proporcionando herramientas analíticas para pensar al estado, para negar su existencia y a la vez para presentarlo como un proyecto ideológico. ¿Cómo entonces se podría estudiar al estado desde una perspectiva antropológica?, sin lugar a duda en varias investigaciones antropológicas se ha discutido, e incluso mantenido, la idea de que el estado está asociado con una imagen de poder que se concentra en el aparato burocrático y los niveles más altos del régimen en el poder, desde el cual se extiende hacia el exterior a través de la nación, y hacia abajo en la vida de la población (Munrray Li, 2005:385).

A pesar de lo planteado, considero necesario romper con la visión del estado como algo coherente, unificado y con autonomía absoluta; rebasando los intentos de conceptualización, para así centrarse en analizar cómo la idea de estado se encuentra en el minucioso entramado de la vida cotidiana, en las acciones, en las organizaciones y en los discursos de individuos. Pero sobre todo en las prácticas culturales donde tanto el estado como los ciudadanos llegan a imaginarse; prácticas insertas en situaciones locales que reflejan realidades mucho más amplias a un nivel macro.

Por ello concuerdo con Gupta al señalar que el reconocimiento de múltiples agencias, organizaciones, niveles, programas y centros conlleva a conceptualizar al 
estado en términos mucho más descentralizados y desagregados. Esto llevará a un análisis de los otros actores sociales e instituciones (comunidades, grupos de interés, sociedad civil, grupos étnicos, partidos políticos, sindicatos u organizaciones campesinas) que son imaginados en los procesos de impugnación, negociación y colaboración con "el estado" (2015:130).

La modificación y apertura del mercado eléctrico a la inversión privada, al igual que el empoderamiento de nuevos actores reguladores de éste, han llevado a especialistas a afirmar que los impactos del neoliberalismo y el mercado transnacional están debilitando y acabando con el estado mexicano. Desde una postura crítica, Linda Weiss asegura que dentro de las ciencias sociales la aparición de tendencias supuestamente nuevas en el mundo en general, como la globalización de los mercados, la pérdida de autonomía nacional, la impotencia de los gobiernos frente al capital transnacional, así como la obsolescencia del estadonación como principio organizador, ha llevado a una nueva era de "negación del estado" (2007:2)

Para Weiss (2007), esta nueva era se ha inundado de discusiones que presagian la disminución o el desplazamiento de los estados como actores de poder en los ámbitos nacional e internacional. Negando con ello no sólo las múltiples respuestas estatales a las presiones globales, sino también la importancia del estado en la estructuración de las relaciones sociales.

Afirmación que remite a lo planteado más arriba por Philip Abrams (2015) sobre la importancia de no renunciar a la idea del estado, abordando así las relaciones de instituciones estatales y sus implicaciones económicas dentro de un marco más general de poder. Weiss por su parte propone centrarse en el análisis de la capacidad transformadora con la que cuenta el estado para la formulación de políticas que permitan aplicar estrategias de ajuste interno que, en cooperación con grupos económicos organizados, mejoren o transformen la economía (2007:7).

Lo anterior conduce al cuestionamiento sobre el papel y capacidad del estado ante su aparente desplazamiento dentro todas las actividades del sector energético mexicano. Si bien Vargas Suárez (2015) reconoce dicho desplazamiento, afirma que el papel del estado dentro de la economía y la política no se suprimió; al ser éste el encargado de establecer las reglas del juego al diseñar la regulación, crear organismos e instituciones del mercado para su operación, así como conservar la capacidad, o en palabras bourdianas conservar su metacapital, para legitimar legal y simbólicamente las relaciones y acciones con los nuevos actores, léase empresas privadas y actores políticos.

Es así como con una amplia autoridad, a través del fortalecimiento y ampliación de las facultades legales, políticas e institucionales de la Secretaría de Energía (SENER), la Comisión Reguladora de Energía (CRE) y el Centro Nacional de Control de Energía (CENACE), el estado mexicano se presenta como un estado con 
anchas facultades para intervenir en la regulación del mercado energético, expandir redes e impulsar el aprovechamiento de fuentes renovables de energía.

Rodríguez Padilla concuerda con lo descrito al señalar que el nuevo marco jurídico permite al estado mexicano, a través de dichas instituciones, ser el encargado de establecer y ejecutar la política, la regulación y la vigilancia de la industria eléctrica. Poniendo énfasis en que este fortalecimiento político y regulatorio de instituciones puede ser visto como la piedra angular del nuevo equilibrio entre el estado y el mercado. En otras palabras, el estado conserva su "papel como propietario, operador e inversionista, además de su papel indefectible de regulador y rector de la actividad" eléctrica (2016: 50).

A pesar de ver lo anterior, en palabras de Linda Weiss (2007), como la capacidad transformadora con la que cuenta el estado mexicano para hacer frente la privatización total del mercado energético del país; existen análisis que señalan que ésta representa la culminación de un estado que no está interesado en salvaguardar el patrimonio territorial. Pues afirman que las reformas aprobadas constitucionalmente se enfocaron en reconfigurar el territorio a partir de las necesidades del capital transnacional; siendo el estado no sólo promotor, sino socio de dichos capitales (Merchand, 2015; Luna Gómez, 2016).

Dentro de la reforma, así como en sus leyes secundarias, se discuten los derechos de propiedad"; proponiendo la "negociación directa" con los propietarios de los terrenos para llegar a acuerdos sobre la ejecución de actividades que van desde la exploración hasta la generación de energía. De acuerdo con el análisis legal realizado por Gutiérrez Nájera (2015), en caso de que no existan acuerdos establecidos con los propietarios de la tierra, la reforma asegura la intervención del Ejecutivo federal para decretar la utilidad pública o el interés social y establecer la ocupación temporal, servidumbres o expropiación, en caso de requerirse, para la realización de las actividades del sector hidrocarburos.

Precisamente lo denominado dentro de la reforma como servidumbre legal, ocupación o afectación superficial, es lo que ha llevado a considerar lo planteado en ésta como estrategias de expropiación de terrenos y la violación de los derechos de pueblos y comunidades, ello a favor de empresas privadas. Huerta Moreno señala que, dentro de la Ley de la Industria Eléctrica, se estipula que la generación, distribución, transmisión y comercialización energética es de interés social y orden público, por lo que tiene preferencia sobre cualquier otra actividad; facilitando con ello la apropiación y explotación territorial de en su mayoría espacios ejidales y comunales por parte de capitales extranjeros. Colocando así los intereses de

\footnotetext{
${ }^{4}$ De acuerdo con la Constitución Política, existen tres tipos de propiedades: la propiedad social correspondiente a ejidos y comunidades indígenas; la propiedad de la Nación, siendo esta la del subsuelo para el caso de hidrocarburos y la propiedad privada.
} 
compañías privadas por encima de los intereses de pueblos y comunidades indígenas (Huerta Moreno, 2015:51).

Por parte del estado mexicano se asegura que con lo decretado en la Reforma y sus disposiciones administrativas se atenderán los principios de sostenibilidad y respeto de los derechos humanos de las comunidades y pueblos de las regiones en los que se pretendan desarrollar5; cumpliendo así con la aplicación y vigilancia del marco jurídico nacional e internacional con el que México se ha comprometido anteriormente, entre ellos el Convenio 169 de la Organización Internacional de Trabajo (OIT). Todo ello a través de metodologías, disposiciones, protocolos de acción coordinados y dirigidos por la SENER, tales como la Evaluación de Impacto social y la Consulta Previa Libre e Informada.

Si bien estas acciones son novedosas y sin precedentes en otros sectores del desarrollo, aún más permite el diálogo entre actores, para Rodrigo Llanes (2017), lejos de ser un derecho vinculado a la libre determinación, la consulta previa a las comunidades no sólo se ha convertido en un mero trámite o procedimiento, sino en una nueva forma de gobierno en que el estado regula y controla a la población. Es decir, a través de esta nueva forma de gobierno el estado decide cómo y a qué personas de la comunidad consultar, desconoce a los representantes comunitarios y excluye a asesores legales y técnicos de las comunidades y a observadores civiles e independientes del gobierno o a cualquier otro actor preocupado por las posibles afectaciones sociales y ambientales de las comunidades.

Como bien señala Cyme Howe (2015b), casi siempre los proyectos energéticos liderados por el estado y la industria son políticamente complicados; especialmente cuando el discurso sobre la transición energética es presentado como una necesidad ambiental, económica y política de todo el país. Discurso que, como se mostró, también puede ser percibido como una amenaza a los intereses locales y a su vez moldear un contra discurso que permita visibilizar la relación compleja y a menudo conflictiva entre los proyectos, los pueblos indígenas y el derecho a la tierra.

Es esta complicación política que me llevaría a seguir nombrando los distintos papeles y percepciones sobre el estado que han surgido a raíz de la transición energética en nuestro país. Por ello, se reconoce que el papel que juega el estado mexicano dentro de la industria y el mercado energético es múltiple, variado (Rodríguez Padilla, 2016) e incluso contradictorio. No solo es presentado, imaginado y percibido a través de sus instancias gubernamentales como legislador, regulador, inversionista, propietario, defensor de los derechos humanos, protector del ambiente y promotor del desarrollo; sino también como un actor desplazado que

\footnotetext{
${ }^{5}$ Ver: Disposiciones Administrativas de Carácter General sobre la Evaluación de Impacto Social en el Sector Energético.
} 
cedió todas sus responsabilidades a empresas extrajeras, por lo que sólo se limita a promover y fomentar la sustentabilidad, la seguridad energética nacional y el respeto a los derechos, no a garantizar y velar por su cumplimiento ${ }^{6}$.

Tener en cuenta la multiplicidad de roles que se atribuye el estado, y los que se le atribuyen a éste, me permite por una parte romper con su figura protagónica, como un representante único y homogéneo; y por la otra dar cabida en esta discusión a los procesos contradictorios que van dirigidos a constituirlo. Así, al atender estas contradicciones, en palabras de Gupta (2015), vemos como el estado mexicano representa legítimamente la nación ante la economía global con un discurso centrado en la importancia de la apertura total del mercado a través de una transición energética que contribuya al desarrollo ambiental, social y económico del país. Pero también cómo este discurso puede potencialmente dar poder a una variedad de actores -activistas, académicos, comunidades indígenas-, al cuestionarlo en materia de derechos humanos y crear con esto posibilidades para la acción política y el activismo.

\section{Megaproyectos y resistencia social}

Como anteriormente se señaló, la reforma energética ha facilitado la entrada de corporaciones mayormente transnacionales interesadas en generar y distribuir energía a través de megaproyectos; mismos que para tal fin se enfocan en el aprovechamiento de los recursos naturales de territorios usufructuados por comunidades rurales e indígenas. Dentro de esta multiplicidad de megaproyectos sobresalen aquellos enfocados en la generación de energía alternativa, que "contribuyen" a las políticas públicas neoliberales de los actuales gobiernos para lograr la "descarbonización" de los sistemas energéticos nacionales.

A pesar de navegar con una bandera verde, estos megaproyectos son señalados al considerar que responden a "las necesidades del sistema económico y del modelo urbano industrial y no de los requerimientos de las poblaciones campesinas en donde se instala o se construyen" (Rodríguez Wallenius, 2015a: 174). Es así que lo anterior, junto con la manera "oficial" en que están siendo evaluados ${ }^{7}$ estos megaproyectos instaurados a lo largo de todo el país, ha sido cuestionado por científicos, activistas, ejidatarios y pobladores rurales al señalar que su aplicación favorece a los intereses económicos de las empresas y en su diseño ignoran el contexto sociocultural y ambiental de los territorios rurales; por lo

\footnotetext{
${ }^{6}$ Muchas de estas críticas realizadas al papel que el estado tomó tras la privatización total y apertura del mercado energético nacional, son construidas desde espacios académicos institucionalizados. Lo que remite a peguntar en términos bourdianos si estas críticas no retoman por cuenta propia un pensamiento de estado o a aplicar al estado unas categorías de pensamiento producidas y avaladas por el estado.

${ }^{7}$ A través de documentos requeridos a las empresas para su autorización institucional, tales como las Manifestaciones de Impacto Ambiental (MIA) y las Evaluaciones de Impacto Social (EVIS).
} 
que su ejecución ocasiona importantes impactos ambientales, sociales y territoriales en los lugares donde se asientan dichas obras.

De acuerdo con Rodríguez Wallenius, en México el despoblamiento de localidades enteras, las expropiaciones de tierras campesinas donde se asientan los megaproyectos (presas hidroeléctricas y represas, termoeléctricas, petroquímicas, parques eólicos o solares, entre otros), así como los otros impactos que tienen estas actividades en la población y en la naturaleza local, son justificadas por los requerimientos de electricidad del país e impulsadas por gobiernos estatales y federales "encubriendo las prioridades de las élites gobernantes y la cúpula empresarial" (2015a: 175).

Estoy de acuerdo con Howe (2015b) cuando señala que tanto las políticas de mercado como las empresas se proclaman como las soluciones más eficaces y "racionales" para el cambio climático antropogénico. Pero lo que intentan cubrir con este manto verde, es que están fuertemente ligados al capitalismo financiero y que se juegan múltiples intereses económicos. Mismos que se relacionan con los propios intereses de las comunidades, en su mayoría indígenas; las cuales se presentan como ganadoras en el desarrollo de estos proyectos al recibir ingresos y pagos por convenios de usufructo.

Siguiendo lo planteado por Lins Ribeiro (1987), los megaproyectos energéticos impulsados por empresas transnacionales pueden ser tratados como expresiones extremas del campo del desarrollo, no sólo por estar ligada a la expansión de sistemas económicos y conectar áreas relativamente aisladas con sistemas más amplios de mercados globales; sino también al contar con grandes tamaños de capital y controlar grandes extensiones de tierra y personas para su funcionamiento; pero también por su magnitud en sus impactos ambientales y sociales; y la complejidad de las redes que de ella emergen (incluyendo las redes contrahegemónicas).

Asimismo, la magnitud de estos grandes proyectos energéticos es acompañada por "un proceso de legitimación que articula varios discursos ideológicos" (Lins Ribeiro 1987:11), principalmente el de progreso y sustentabilidad. Así, tanto las empresas desarrolladoras como los representantes de organismos gubernamentales presentan los proyectos como oportunidades de desarrollar las regiones indígenas, colocándolas en mercados globales, y a su vez suministrando bienestar a todo el mundo al contribuir a la generación de energía limpia

La generación de empleo también es presentada como otra de las oportunidades para liberar del atraso y pobreza las comunidades cercanas a la zona donde se construirán dichos proyectos. De acuerdo con las empresas desarrolladoras, debido a su magnitud éstas necesitarán emplear mano de obra en la fase de preparación, construcción, operación; pero también en las actividades complementarias; e incluso se presentan como oportunidades para impulsar negocios locales. 
Si bien es cierto que estos proyectos pueden generar ciertas ofertas de empleo, también lo es que las poblaciones locales y de áreas vecinas muy posiblemente sean incorporadas en las posiciones más bajas del mercado de trabajo; esto debido a que los proyectos de este tipo "poseen un circuito migratorio propio y que la cantidad de empleos creados guarda una proporción baja con respecto a los montos gigantescos de las inversiones" (Lins Ribeiro 1987:5).

Analizando los megaproyectos como modelo de despojo, Rodríguez Wallenius (2017) señala que la disputa del territorio y los bienes naturales de las poblaciones rurales implican grandes afectaciones que son silenciadas en pro del desarrollo y por lo tanto asumidas únicamente por comunidades campesinas e indígenas. Para entender la dinámica económica de los proyectos a gran escala, este autor propone una categoría analítica que ha denominado despojo para la acumulación.

Dicha categoría analítica es presentada como una alternativa a las categorías de acumulación por desposesión ${ }^{8}$ y extractivismo, al señalar que resalta relaciones y procesos que comúnmente no aparece en los debates de estas dos últimas categorías. Rodríguez Wallenius, define a esta categoría como una de las tendencias que los grupos económicos impulsan para apropiarse tanto de bienes naturales y comunitarios, como de bienes públicos; lo que les permite obtener altas rentas a partir de ganancias extraordinarias generadas cuando esos bienes son incorporados y valorizados como mercancías en los mercados de productos o en el sistema financiero (2017:51).

En el caso de los megaproyectos energéticos es posible observar una apropiación empresarial de tierras ejidales para asentar la infraestructura a gran escala, desde aerogeneradores hasta paneles fotovoltaicos, que permita la generación de energía; misma que, de acuerdo con el ciclo de acumulación, al ser insertada dentro del mercado energético mundial adquiere, por su alta rentabilidad, una valorización. Recordemos así la importancia del territorio dentro de los proyectos de generación, distribución y comercialización de energía.

Dentro de la reforma se establece que la generación de energía será de interés social y orden público por lo que tendrá preferencia sobre cualquier otra que implique el aprovechamiento de la superficie y del subsuelo de los terrenos, incluyendo núcleos agrarios, seleccionados para tal fin. De igual forma esta reforma trajo consigo la instauración de un marco legal-normativo, incluyendo la constitución de figuras e instituciones gubernamentales, que facilitan la ocupación, uso o disposición de territorios $u$ otros bienes para realizar actividades energéticas.

8 Propuesta desde la geografía crítica, esta categoría analítica tiene como referente principal lo planteado por David Harvey sobre la modalidad de acumulación del sistema capitalista actual; misma que demuestra su incapacidad y limitaciones de acumulación mediante la reproducción ampliada del capital, por lo que se basa en la depredación y mercantilización de bienes naturales y comunales. Ver: Harvey, 2004 
Nos encontramos no sólo ante disposiciones legales que permiten la apropiación por parte de agentes externos de territorios rurales seleccionados por cumplir con características que la actividad demanda, sino también ante un contexto de disputa de significación, de relaciones sociales y de control territorial. Vemos así al territorio como un espacio apropiado socioculturalmente que contiene vínculos de pertenencia; pero también como un espacio en el que se ejercen relaciones de dominio y control, poniendo en relieve las relaciones de poder y conflicto entre actores.

Rousseau (2017) distingue dentro de los proyectos energéticos tres principales grupos de interés con respecto al territorio; en primer lugar, se encuentran las compañías trasnacionales quienes vienen respaldadas y asesoradas económica y legalmente, pero también conociendo las políticas internas y la dinámica del mercado energético global; en segundo lugar, se encuentra el estado al ocupar una posición ventajosa: ser el mediador final y quien establece las reglas del juego. Por último, se encuentran las comunidades campesinas e indígenas, quienes desconoce no sólo de la industria y sus dinámicas políticas y económicas, sino también de la valorización capitalista de la tierra dentro del mercado energético.

Rodríguez Wallenius (2015b) muestra como dentro del proceso de apropiación del territorio y bienes naturales, las empresas, en conjunto con el estado, instauran una territorialidad, es decir un conjunto de prácticas, acciones y relaciones sociales que construye material y simbólicamente un territorio frente a otras formas de construirlo, lo que representa un proceso de disputa. Metodológicamente este autor tiende una invitación a ver el espacio como un campo de conflicto para analizar cómo interactúan los grupos hegemónicos, que respaldados por el estado encuentran una legitimación de sus actividades de despojo, con actores locales que cuestionan estas actividades a gran escala, se movilizan y resisten a través de la construcción de su propia territorialidad y en defensa de sus territorios y recursos naturales.

Tal como señala Martínez Reséndiz, estos movimientos están relacionados "con la defensa de sus territorios afectados por las políticas de desarrollo implantadas por el estado mexicano, así como con la consecuente exigencia de respeto a los derechos violados" (2013: 366-367). Por su parte, Miguel Ángel Sámano afirma que actualmente hay dos tipos de movimientos campesinos en resistencia; por una parte el de carácter regional conformado por diferentes actores y que son movimientos autogestivos en defensa de la tierra y agua en particular; y por otra aquel mucho más amplio en "el que se defiende el territorio de una región que se verá afectada por el impulso de un megaproyecto, amenazando la tenencia de la tierra e implicando el despojo y desplazamiento de las poblaciones de sus lugares de origen" (2017:15). 
A pesar de esta diferenciación señala que varios de estos movimientos son de pueblos indígenas que se identifican con una región y cultura y que tienen como objetivo suspender los proyectos o lograr que un decreto o un contrato de arrendamiento se anule con el fin de proteger los intereses colectivos de los actores sociales que participan en los movimientos. Esto a través de la lucha legal y la movilización social, es decir, desde las manifestaciones públicas, bloqueos carreteros, hasta el uso de recursos legales como la ley nacional, el marco jurídico internacional y el uso del litigio y el cabildeo con instituciones del estado y empresas.

Con base en el estudio de los movimientos de resistencia puestos en marcha por las poblaciones rurales del Istmo de Tehuantepec, Noé Hernández demuestra que además de incluir a diferentes actores sociales estos movimientos confluyen con movimientos regionales más amplios y redes de diferentes organizaciones en resistencia. Ya que señala que, al constituirse una identidad política, los pobladores de esta región no sólo lideran una lucha política articulada de discursos y demandas sociales como son el respeto a los derechos humanos, el sentido colectivo de la tierra y el derecho a la consulta previa, libre e informada, sino también logran compartir significados de lucha y estrategias con otros actores al establecer redes de apoyo político con organizaciones comunales indígenas zapotecas y otros movimientos opositores a los megaproyectos eólicos (2015:22).

De acuerdo con Navarro, si bien históricamente se han registrado procesos de resistencia por la lucha y defensa de los bienes comunes naturales, principalmente de la tierra, actualmente éstos han sufrido transformaciones debido a que hoy en día los campesinos y comunidades indígenas se enfrentan a altos niveles de violencia, agresividad y voracidad capitalista (2013:76). La autora afirma que a pesar de esta transformación, los actores insertos en estos movimientos de resistencias mantienen el histórico y profundo vínculo con el territorio; el cual, ante su fortalecimiento, ha sido "fundamental para el despliegue de horizontes políticos para la autodeterminación [...] y la emergencia de nuevas subjetividades políticas" que les permite ir más allá de las relaciones sociales que los oprimen y "construir relaciones horizontales de solidaridad y apoyo entre las diferentes resistencias para la expansión, cobertura, visibilidad y fortalecimiento de las capacidades sociales contra el despojo" (Navarro, 2013:77-80).

Del mismo modo Ana de Ita menciona que actualmente existen cientos de luchas locales en defensa de las tierras de los pueblos y de sus recursos, mismos que son codiciados por distintos agentes que pretenden insertar una serie de proyectos en pro del desarrollo. Esta lucha de resistencia es llevada a cabo por campesinos y comunidades indígenas que incluso logran recuperar la "figura de pueblos" e incluir en la lucha al resto de los pobladores y a quienes se asumen como parte de una historia común en el lugar. Es por ello por lo que señala que "en un entorno de cada vez mayores amenazas de despojo a los territorios de los indígenas y campesinos, las luchas se multiplican y recrudecen" (2010:28). 
Me parece importante señalar que cada de uno de los autores y casos aquí expuestos identifican elementos claves que caracterizan estas "luchas de resistencia"; entre ellos territorio e identidad, motivaciones políticas, discursos que visibilizan las demandas sociales y estrategias colectivas en defensa de la tierra. Si los consideramos como dimensiones de análisis, estos elementos permiten reflexionar la manera en cómo se involucran con la categoría conceptual de resistencia. Si bien los autores consultados no realizan una discusión de este concepto para guiar sus investigaciones, éstas sí permiten cuestionar quiénes están en resistencia, desde dónde y por qué surgen estos movimientos.

Zárate Vidal (2008), reconociendo que la palabra resistencia está presente en los discursos de una diversidad de actores sociales y que por ello resulta particularmente central para la antropología, realiza una discusión teórica en la que señala que está categoría se encuentra fuertemente ligada con otras categorías tales como poder, ideología y hegemonía, poder y cultura, agencia y discurso. Concluye que la conceptualización de resistencia se complica por los diferentes tipos de agencia y agenda de los actores, pero que sigue estando en el centro de reflexión del medio académico.

\section{3. ¿Hay cabida dentro de la transición energética para la antropología?}

There are cracks in the foundations of energy research and policy, creating a space for anthropologist to move in and make a contribution.

Harold Wilhite, 2005

En los últimos años se ha documentado y discutido los cambios en el sistema energético global, las reformas constitucionales en materia energéticas, así como la apertura de los mercados y la privatización de la energía en países latinoamericanos. Sin embargo, los estudios que se han realizado con perspectivas antropológicas aún comienzan a ganar fuerza; por ello el planteamiento de Wilhite (2005) de por qué la energía necesita antropología, parece responder otros cuestionamientos sobre el lugar que esta ciencia social puede, o no, ocupar dentro de los análisis de la transición energética en México.

Es verdad que desde la economía y las ciencias políticas se ha analizado cómo dicha transición responde a agendas políticas y modelos económicos interconectados a la actual economía global. Pero también lo es que ambos enfoques dejan fuera de la discusión las múltiples relaciones sociales, las prácticas culturales y la resignificación dentro del entramado de la vida cotidiana de las reformas en materia energética; en general no toman en cuenta que la generación, distribución y comercialización de energía, así como las políticas detrás de ésta, se 
involucran y están integradas de igual modo con sistemas socioculturales en distintos niveles ${ }^{9}$.

Para Wilhite, estos vacíos demuestran que el estudio de la energía necesita innovaciones teóricas, incluyendo las contribuciones antropológicas. Mismas que podrían ofrecer una mejor compresión no sólo de cómo las relaciones familiares, de género, las relaciones de producción, el significado y la moral están mutuamente implicados en los usos de la energía; sino también cómo dentro de todo el proceso de generación de energía y consumo se construyen relaciones sociales, discursos (incluyendo aquellos del calentamiento global y la importancia de contribuir a la reducción de emisión de CO2), así como redes de poder (2005:2).

En el mismo sentido, Winther y Wilhite (2015) aseguran que existe una reactivación del interés antropológico en la energía, principalmente en temas relacionados con cuestiones de cambio climático, seguridad energética y agotamiento del petróleo. Basados en esto, los autores afirman que el estudio de la electrificación es esencial para comprender no solo la transformación de las experiencias culturales locales, sino también una creciente interconexión translocal y sus implicaciones humanas (2015:570).

Con ello, es válido argumentar que se presentan nuevos desafíos teóricos y empíricos para los antropólogos interesados en identificar los cambios y las dinámicas socioculturales que los proyectos energéticos producen. Como se presentó en párrafos anteriores, diversos estudios han documentado los impactos sociales y ambientales que los megaproyectos energéticos han producido en las dinámicas locales de poblaciones campesinas e indígenas. Se ha mostrado cómo estos proyectos a gran escala están enredados en sistemas políticos y económicos que propician un acceso desigual a los servicios, recursos y ganancias dentro del mercado energético.

A pesar de estas contribuciones, considero que los estudios sobre políticas y megaproyectos energéticos tienen un mayor interés en documentar las respuestas y estrategias de las poblaciones rurales ante la defensa de su territorio; de tal manera que las nuevas relaciones que se entretejen dentro de estas dinámicas de inserción política y económica de proyectos a gran escala se analizan desde -en palabras de Abélès y Badaró (2015) — "obsesiones antropológicas", como el caso de la noción de resistencia y los sentidos del lugar (territorio).

Dentro de esta reflexión precisamente encontramos las críticas sobre la obsesión de la antropología con la resistencia. En este sentido Lila Abu-Lughod, afirma que la resistencia se ha convertido en los últimos años en un foco popular

\footnotetext{
${ }^{9}$ En su obra Carbon Democracy: Political Power in the Age of Oil, Mitchell (2011) asegura que la economía política trata a la energía y al medio ambiente como exógenos para la sociedad; cuando éstas, en conjunto con el desarrollo y el poder político están integrados socialmente a un nivel local, nacional y global.
} 
para el trabajo en las ciencias humanas, sin embargo, los estudios están más preocupados por encontrar resistencias y explicar la resistencia que por examinar el poder. Por lo que, a pesar de la sofisticación teórica de muchos estudios antropológicos e históricos de la resistencia cotidiana, sigue habiendo una tendencia a romantizarla (1990:41).

Esta autora sostiene que la resistencia debe usarse como un diagnóstico de poder y no para resaltar únicamente la dignidad o heroísmo de los que resisten. Volcar la mirada hacia la idea de que "donde hay resistencia, hay poder" permitirá que la resistencia sea usada estratégicamente para contarnos más sobre las formas de poder y cómo las personas se encuentran atrapadas en ellas. Mucho más, permitirá detectar cambios históricos en las configuraciones o métodos de poder (Abu-Lughod, 1990:48).

Por su parte Gutman (2012), argumenta que la exagerada celebración de la agencia popular ha influido en las pocas herramientas teóricas para analizar no sólo la resistencia fallida, sino también frecuencia de la sumisión, colaboración, apatía y pasividad. Por lo que señala la urgencia de comprender las dialécticas de la movilización, la apatía, la resignación y la culpa bajo el concepto "compliant defiance".

Otra de la crítica a la noción de resistencia es defendida por Sherry Ortner cuando señala que los trabajos acerca de la resistencia adolecen de serias limitaciones debido a la ausencia de una perspectiva etnográfica incapaz de abordar la política interna de los grupos dominados, la riqueza cultural de esos grupos o la subjetividad -las intenciones, los deseos, los temores, los proyectos- de los actores que participan en estos dramas. Crítica dirigida aun cuando ella considera que a pesar de su ambigüedad la resistencia es una categoría útil por poner en relieve la presencia y el funcionamiento del poder en las formas de relación y actividad (2016:59).

Poniendo énfasis en la ambigüedad de la resistencia y la ambivalencia subjetiva de los actos para los participantes, esta autora señala que no existe un subordinado único y unitario; pero sí diferentes posicionamientos de estos actores en las relaciones de poder. Asimismo, el vacío que indica en los estudios de resistencia al centrarse únicamente en la política de la relación entre el dominador y el subordinado se debe a que dejan a un lado la política de los que resisten. Esta omisión en las políticas internas provoca que las resistencias individuales, los conflictos, las contradicciones internas y las emociones ambivalentes existentes en los movimientos de resistencia a gran escala sean totalmente dejados fuera del análisis (Ortner, 2016:64)

Tenemos así que el caso de las movilizaciones y resistencia que se han ido consolidando tras la inserción de megaproyecto energéticos, ha dado lugar a muchas interpretaciones románticas sobre la figura del campesino-indígena. Como señala Howe (2015b), elogiar el conocimiento indígena y evocar la administración 
autóctona de la tierra ha sido una lógica inmediata y poderosa para la resistencia, aunque el grupo corra el riesgo de ser reducido a interpretaciones esencialistas. Por ello, lo planteado hasta acá no es una crítica a la categoría de resistencia como tal, si no más bien a la manera en que ha sido utilizada; dejando fuera del análisis los diferentes posicionamientos de los subordinados, así como las relaciones de poder que se han ido fortaleciendo tras la apertura del mercado energético, las reformas estructurales y en general tras la inserción de comunidades rurales a la lógica del mercado energético global.

De igual modo, la mayoría de los trabajos sobre movimientos sociales contra megaproyectos energéticos muestran una imagen homogénea de la resistencia de poblaciones indígenas e incluso afirman que éstas entraron en inestabilidad ante la presencia de estos procesos de desarrollo, por lo que aquellos casos que demuestran que no toda la población resiste no son considerados como parte de la investigación y son catalogados como excepciones.

Apegarnos a las críticas de la noción de resistencia permitirá pues demostrar que no nos encontramos ante un sistema cultural integrado, sino en uno en el que se pueden observar posicionamientos y creencias totalmente diferentes que coexisten y son usados en diferentes situaciones. Así prestar atención a las diferentes percepciones del mismo fenómeno nos facilitará rastrear las políticas internas, así como la posible división y conflicto comunitario. Pero sobre todo romper con la idea de homogeneidad y equilibrio perpetuo comunitario.

La necesidad de innovaciones teóricas que Wilhite propone para el análisis de la energía, y acá incluiría el análisis de cómo las políticas económicas en materia energética se entretejen en la vida social, podría cubrirse desde la antropología política. Una visión crítica desde esta perspectiva antropológica permitirá ofrecer una imagen de la participación del estado, las empresas privadas y las comunidades rurales más allá de meras relaciones opuestas entre actores. $O$ en palabras de Abélès y Badaró una postura critica permitirá que dentro de los estudios de la vida política se rompa con imágenes binarias: los arcanos del poder y los sin voz; el grande y el pequeño; el distante y el cercano; el todopoderoso y el desposeído; el poder y la resistencia (2015:11).

La contribución de la antropología política podría residir en discernir y poner al descubierto esas políticas internas y los diferentes posicionamientos de los múltiples actores en las nuevas relaciones de poder, más allá de ver al estado como el que encarna el poder y las comunidades rurales como silenciadas y oprimidas. No romper con este enfoque podría ocasionar que las múltiples voces y agencias sigan siendo reducidas a representaciones estereotipadas sobre las personas, los lugares y el poder. Ya que como señalan Abélès y Badaró, la antropología expresa su carácter político cuando se dispone a captar esas multiplicidades y flujos vitales, inmanentes a diferentes ámbitos y escenarios de la vida social (2015:13). 
Al respecto, Isabelle Rousseau en un estudio sobre los megaproyectos energéticos en México, defiende firmemente la necesidad de acabar con el hábito de caracterizar con prejuicios a los diferentes grupos de interés involucrados en estos proyectos a gran escala (léase estado, empresas, poblaciones rurales); ya que "no todas las comunidades son atrasadas y carecen de información ni todos los desarrolladores evaden su responsabilidad en cuanto a impacto social" (2017:215). Esta construcción, más allá de lo planteado en artículos académicos, imposibilita que se dé un diálogo real entre los actores, dialogo que bien podría incorporar propuestas, demandas y perspectivas de las diferentes partes interesadas.

De igual forma, captar estas multiplicidades permite entender cómo el discurso estatal moldea la vida cotidiana, las acciones, las organizaciones y los discursos de individuos. Dentro de la lógica de la transición energética las comunidades rurales también tienen un gran compromiso, como ciudadanos, en combatir el cambio climático; por lo que, desde términos morales, funcionarios de instituciones como la Secretaría de Energía difunden este discurso para lograr la aceptación social de los proyectos.

Como contraparte, las comunidades que se organizan, en conjunto con activistas y académicos, readaptan este mismo discurso para defender su territorio, para señalar que apoyados por el estado los proyectos a gran escala representan repercusiones ambientales a nivel local al ocupar y devastar grandes extensiones de tierra. Se ha visto así que se ha configurado un discurso que visibiliza las demandas sociales y los movimientos opositores a los megaproyectos. Este discurso, al encontrar su base en la identidad étnica y los derechos indígenas, se convierte en una expresión política, jurídica y de gobernanza ${ }^{10}$, donde el estado es imaginado y toma distintos roles: el que facilita el despojo o el que protege los derechos.

Ejemplo de ello es que aquellas personas que se organizan y forman parte de las movilizaciones contra los megaproyectos energéticos y políticas federalesestatales, han recurrido a organismos como el Tribunal Unitario Agrario para denunciar las violaciones a los derechos indígenas tras la inserción de estos proyectos a gran escala dentro de su territorio. Deborah Poole, nos muestra con un trabajo etnográfico sobre los márgenes del estado, cómo los campesinos de Perú invierten su deseo de justicia en el estado, incluso cuando la ilegibilidad del estado y de sus procesos frustren esos deseos, ya que los documentos necesarios para asegurar justicia tienden a moverse sin fin entre diferentes jurisdicciones (2008:38).

Importante también prestar atención en lo que ocurre dentro del interior de las movilizaciones, sus contradicciones, deseos e intereses individuales, así como

\footnotetext{
${ }^{10}$ Rodríguez Garavito (2011) emplea el concepto "etnicidad.gob" para analizar los procesos jurídicos de las reivindicaciones y demandas étnicas. Plantea también que tanto la identidad étnica como los derechos indígenas se han convertido en una cuestión de gobernanza.
} 
el posicionamiento de los actores. Si bien es cierto que dentro de las movilizaciones rurales ningún actor podría asegurar que está en contra de contribuir a reducir los impactos del calentamiento global o la generación de energía alternativa, sí hay quienes buscan establecer acuerdos con las empresas, quienes más allá de resistir para conservar un vínculo simbólico con la tierra desea establecer contractos de arrendamiento con estos agentes externos.

Siguiendo lo planteado por Gupta (2015), sobre cómo las representaciones del estado se efectúan a través de las practicas públicas de diferentes instituciones y agentes gubernamentales. Sería interesante conocer cuál ha sido el papel de instancias y funcionarios del gobierno dentro de las organizaciones ejidales. En una plática informal recogida en campo, un ejidatario de una población de Yucatán aseguraba que antes de que se presentara la empresa impulsora de un megaproyecto fotovoltaico, un cacique local y un empleado de la Procuraduría Agraria, a través de practicas corruptas, lograron que se celebré un contrato de compraventa de tierras avalado por la Registro Agrario. Al enterarse que las tierras serían cedidas a la empresa transnacional comenzaron a representar tanto a ésta como al estado, a través de sus instituciones, como corruptas e ilegales.

Más tarde con la participación de otros funcionarios de la Secretaría de Energía y personal de la empresa, comenzaron a ver al estado ya no como el dador (en esta lógica del paternalismo gubernamental) sino como el aliado que facilitó que la empresa se comprometiera a pagar 30 mil pesos trimestrales a cada ejidatario por la renta de tierras donde se asentará el proyecto. Así, queda claro que "los funcionarios de nivel inferior representar un papel crucial en los encuentros con los ciudadanos con el estado" (Gupta, 2015:97).

Pero también que dentro de las dinámicas de inserción de megaproyectos se ha consolidado todo un "campo del desarrollo" (Lins Ribeiro, 2007) compuesto por actores que representan varios segmentos de poblaciones locales (empresarios de la zona- líderes comunitarios); funcionarios de dependencias gubernamentales; por políticos en todos los niveles de gobierno; por personal de la empresa (consultores y representantes jurídicos tanto de México como de otras partes del mundo); de organizaciones no gubernamentales (ONG's) y activistas; pero también de académicos e investigadores. Cada uno con voces, intereses y agendas totalmente distintas.

Para finalizar quiero justificar la necesidad de plantear de fondo los aspectos más importantes de la reforma energética; ignorarlos no permitiría la compresión de cómo ésta ha impactado o generado nuevas relaciones sociales y de poder dentro de las poblaciones rurales del país. El análisis de las reformas estructurales y sus impactos, junto con una perspectiva antropológica crítica que rompa con la fetichización de lo silenciado y de lo marginado, pueden bien representar parte de los nuevos enfoques dentro del estudio de la energía y lo político. 


\section{Bibliografía}

Abeles, Marc y Máximo Badaró.2015. Los encantos del poder. Desafíos de la antropología política. Buenos Aires: Siglo XXI editores.

Abu-Lughod, Lila. 1990. "The romance of resistence: trancing transformations of power through Bedouin Women". American Ethnologist 17(1):41-55

Abrams Philip. 2015. "Notas sobre la dificultad de estudiar el estado". En Abrams Philip. Akhil Gupta y Timothy Mitchell (eds), Antropología del estado. México, FCE.

Bordieu, Pierre 1997 "Espíritu de Estado: Génesis y estructura del campo burocrático" En Razones Prácticas: sobre la teoría de la acción. Barcelona, Anagrama.

Clavellina Miller, José Luis.2014. "Reforma energética, ¿era realmente necesaria?”. Economía Informa 385:3-45.

Das, Veena y Deborah Poole. 2008. "El estado y sus márgenes. Etnografías comparadas". Cuadernos de Antropología Social, 27: 19-52.

De Ita, Ana. 2010. "Territorios indígenas y campesinos en México: entre el despojo y la resistencia, primer esbozo de un mapa”. Revista Pueblos y Territorios (001): 21-42.

Gutman, Matthew. 2012. "Raising Utopias from dead in Mexico city and Oaxaca", en Glendhill, Jhon y Patience A. Schell (eds) New approaches to resistence in Brazil and Mexico, London: Duke University Press, 305-324.

Gupta Akhil. 2015. "Fronteras borrosas: el discurso de la corrupción, la cultura de la política y el estado imaginado" En Abrams Philip. Akhil Gupta y Timothy Mitchell (eds), Antropología del estado, 71-134. México, FCE.

Gutiérrez Nájera, Raquel. 2016. “¿Está preparado México para el fracking? Reforma energética en México". Sociedad y Ambiente, 1(9): 102-120.

Hernández Cortez, Noé. 2016. "Energía eólica, identidades políticas y discurso: los casos de Unión Hidalgo y Juchitán de Zaragoza en Oaxaca, México". FRONTERAS Vol. III (1):9 -33. 
Howe, Cymene. 2015a. "Latin America in the Anthropocene: Energy Transitions and Climate Change Mitigations". The Journal of Latin American and Caribbean Anthropology, 20 (2): 231-241.

Howe, Cymene. 2015b. "Los márgenes del Estado al viento: autonomía y desarrollo de energía renovables en el sur de México". The Journal of Latin American and Caribbean Anthropology, 20 (2): 285-307.

Huerta Moreno, Guadalupe.2015. "Las leyes secundarias en el ramo energético y el despojo social" En: Juan Mendoza Pérez y José María Martinelli (Coords.) Reformas estructurales: privatización y despojo social. México: UAM.

Senado de la República. 2015. "Nota legislativa. Ley de transición energética". Instituto Belisario Domínguez.

Llanes Salazar. 2017. "Nueva forma de gobierno". Diario de Yucatán, 9 de octubre.

Lins Ribeiro, Gustavo.1987. ¿Cuánto más grande mejor? Proyectos de gran escala: una forma de producción vinculada a la expansión de sistemas económicos. Desarrollo Económico, 27(105): 3-27.

Lins Ribeiro, Gustavo. 2007. "Poder, redes e ideología en el campo del desarrollo". Tabula Rasa, 6: 173-193.

Luna Gómez, Luis Alberto. 2016. "Escalas y determinaciones en la reforma a la propiedad de los energéticos: México".e-l@tina. Revista electrónica de estudios latinoamericanos, 14(54):35-50.

Martínez Reséndiz, Juana. 2013. "Conflictos étnicos y resistencia de los pueblos en México". En Gutiérrez Chong, N., Etnicidad y conflicto en las Américas: violencia y activismo político, 365-399. México: iis-unam.

Merchand, Marco. 2015. "Estado y reforma energética en México". Revista Problemas del Desarrollo, 183(46): 117-139.

Navarro, Mina. 2013. "Las luchas indígenas y campesinas contra el despojo capitalista en México: subjetividades políticas en la defensa y gestión de los bienes comunes naturales". Boletín Onteaiken (15):71-84.

Ortner, Sherry. 2016. Antropología y teoría social: Cultura, poder y agencia. San Martín: Universidad Nacional de Gral. San Martín. UNSAM EDITA. 
Rodríguez Padilla, Victor. 2016. "Industria eléctrica en México: tensión entre el Estado y el mercado". Revista Problemas del Desarrollo, 185 (47):33-55

Romo Rico, Daniel y Vidal Ibarra Puig, 2009. "La inversión extranjera directa en México: el caso del sector energético”. Comercio exterior, 59 (12):994-1009.

Rousseau, Isabelle. 2017. "La nueva regulación de la gestión social de los proyectos energéticos en México. Seguridad, sustentabilidad y gobernabilidad". Revista Mexicana de Ciencias Políticas y Sociales, 230:197-220

Sámano Rentería, Miguel Ángel. 2017. "Movimientos de resistencia campesina e indígena contra los megaproyectos y el modelo extractivista". El Cotidiano (201): 716.

Secretaría de Economía (SE).2013. Energías Renovables. Unidad de Inteligencia de Negocios. ProMéxico.

Radcliffe-Brown, A. R. 2010. "Prefacio" En Meyer Fortes y Evans Pritchard (eds), Sistemas políticos africanos. México, UAM-I/CIESAS/UIA.

Rodríguez Wallenius, Carlos. 2015a. "Acciones comunitarias contra megaproyectos en México". Revista Geonordeste, XXVI (1): 173-196.

Rodríguez Wallenius, Carlos. 2015b. Geopolítica del desarrollo local. Campesinos, empresas y gobiernos en la disputa por territorios y bienes naturales en el México rural. México: Editorial Itaca/ UAM-X.

Rodríguez Wallenius, Carlos.2017. "Despojo para la acumulación. Un análisis de los procesos de acumulación y sus modelos de despojo”. Bajo el volcán, 17(26):41-63.

Tania Murray, 2005 "Beyond "the State" and Failed Schemes" Current Anthropology. Vena Daas y Deborah Poole. 2008. El Estado sus márgenes. Etnografías comparadas. Cuadernos de Antropología Social, (27), 19-52.

Vargas Suárez, Rosio. 2010. "El sector eléctrico mexicano: ¿nuevos espacios para las corporaciones trasnacionales? Acta Sociológica, 54: 119.139.

Vargas Suárez, Rosio.2015. "Reforma energética. De servicio público a modelo de negocios" Política y Cultura, 43:125-145. 
Wilhite, Harold. 2005. "Why energy needs Anthropology". Anthropology Today 21(3):1-3.

Winther, Tanja y Harold Wilhite, 2015. "Tentacles of modernity: why electricity needs anthropology”. Cultural Anthropology 30(4): 569-577.

Weiss, Linda. 2007. The Myth of the powerless state. Governing the economy in a global era. Polity Press

Zárate Vidal, Margarita. 2008. "De resistencias, sujetos y agencia. Comunidad, etnicidad y resistencia". 
DIRECTOR: DR. HÉCTOR TEJERA GAONA

LA ALUMNA PRESENTó El ENSAYo TITULADO:

El estado y sus reformas estructurales en materia energética: megaproyectos, territorio y movimientos de resistencia en zonas rurales de México

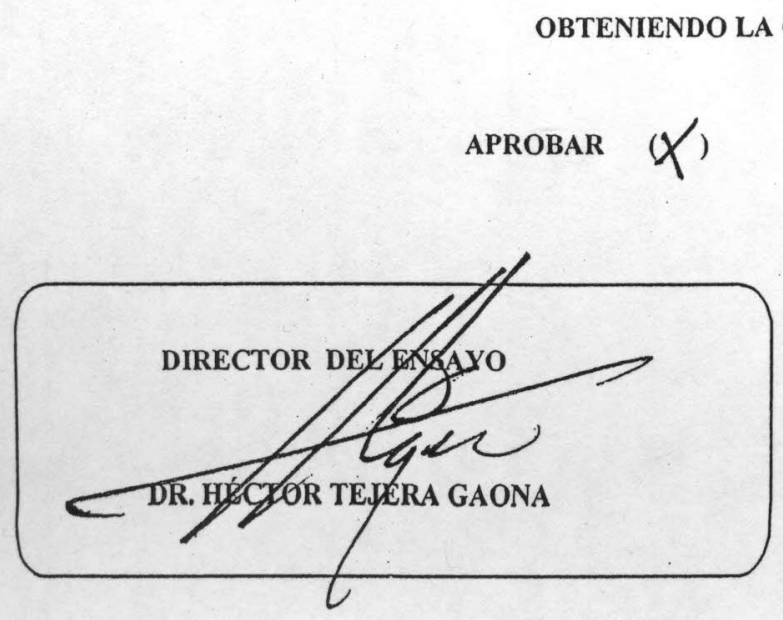

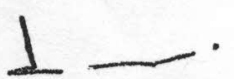

DR. PABLO CASTRO DOMINGO . 
Fecha: $25 / 02 / 2020$

(día / mes / año)

\section{Representante Legal}

\section{Universidad Autónoma Metropolitana}

Presente

Gisela Elizabeth Tucuch Santos alumno(a) del programa de posgrado Ciencias Antropologicas con número de matrícula 2183800279 manifiesto bajo protesta de decir verdad ser el autor (es) intelectual de la presente tesis de grado (obra) titulada "El estado y sus reformas estructurales en materia energética: megaproyectos, territorio y movimientos de resistencia en zonas rurales de México" y que esta es una obra original, la cual no tiene contenido lascivo contra terceros, por lo que de conformidad con los artículos 26 y 27 de la Ley Federal del Derecho de Autor, autorizo a la Universidad Autónoma Metropolitana para que por tiempo indeterminado y de manera gratuita, haga uso de mi obra para consulta, descarga total o parcial, difusión, reproducción en cualquier medio físico o electrónico, adecuación de formato con fines académicos, de investigación y sin fines de lucro, siempre y cuando la Universidad Autónoma Metropolitana respete los derechos morales que ostento como autor, conforme a los artículos 18 y 21 de la citada Ley.

Asimismo, me hago consciente y sabedor de que a través del acceso abierto en el repositorio de la Universidad Autónoma Metropolitana, mi obra estará considerada como divulgación previa con todas las implicaciones que se derivan de ello.

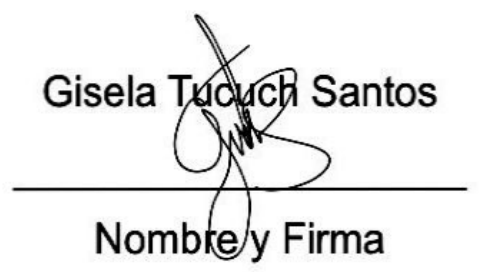

